\title{
GÊNERO E SOCIEDADE: EXPLICAÇÕES DE SUAS RELAÇÕES E EFEITOS EDUCACIONAIS
}

\author{
Alencar Zidani Manuel da Silva ${ }^{1}$, Raul Aragão Martins ${ }^{2}$ \\ ${ }^{1}$ Graduando em Licenciatura em Letras (Português - Francês) pela Universidade Estadual Paulista - UNESP, Campus de \\ São José do Rio Preto, SP. Bolsista do Programa Institucional de Bolsa de Iniciação à Docência (PIBID) pela \\ Coordenação de Aperfeiçoamento de Pessoal de Nível Superior (CAPES). E-mail: alencar.silva@unesp.br \\ ${ }^{2}$ Doutor em Psicologia pela Fundação Getúlio Vargas - FGV, RJ. Livre-Docente em Psicologia da Educação pela \\ Universidade Estadual Paulista - UNESP. Docente associado do Dept. Educação do Instituto de Biociências, Letras e \\ Ciências Exatas da Universidade Estadual Paulista - IBILCE/UNESP. Credenciado como orientador e docente no \\ Programa de Pós-Graduação em Educação da Faculdade de Filosofia e Ciências da UNESP (Campus de Marília). ORCID \\ iD: https://orcid.org/0000-0001-6495-731X. E-mail: raul.martins@unesp.br
}

\section{RESUMO}

O presente artigo trabalha as concepções de Vygotsky (1987) sobre a relação entre pensamento e linguagem sob uma perspectiva de influência no desenvolvimento cognitivo e na formação da visão sobre o gênero proposto pela escola. Neste sentido, notou-se também a construção de estereótipos compreendidos por Brunneli (2016) como grandes influências no comportamento social e no discurso, relacionando-se, por essa perspectiva, e mostrando-se capazes de explicar ações e interações que são estudadas pela psicologia social. Não obstante, recorreu-se aos estudos de Cunha e Góes (2002), Xavier, Ribeiro e Noronha (1994) para compreender como a formação desses estereótipos que foram disseminados influenciaram a organização educacional e cooperaram para a manutenção do status quo, isto é, da desigualdade social e das suas justificativas. Outrossim, para compreender as novas questões que surgem sobre a sexualidade, foi preciso analisar os estudos de Louro (1997) e Oliveira e Santos (2012) para compreender essas novas dinâmicas e perspectivas que surgem para pensar uma escola preocupada com o presente, deixando de lado suas preocupações com o ontem. Por isso, foi percebido como essas relações coexistiram e fomentaram uma organização social pautada em um propósito em não somente justificar as relações hierárquicas de poder, mas também mantê-las utilizando setores estratégicos como a educação e, consequentemente, a escola.

Palavras-chave: Gênero, Pensamento, Educação, Família, Escola.

\section{GENDER AND SOCIETY: EXPLANATIONS OF THEIR RELATIONS AND EDUCATIONAL EFFECTS}

\begin{abstract}
This article works on Vygotsky's (1987) conceptions of the relationship between thought and language from a perspective of influence on cognitive development and the formation of the view on gender proposed by the school. In this sense, we also noted the construction of stereotypes understood by Brunneli (2016) as major influences on social behavior and discourse, relating, from this perspective, and being able to explain actions and interactions that are studied by social psychology. Nevertheless, the studies of Cunha and Góes (2002), Xavier, Ribeiro and Noronha (1994) were used to understand how the formation of these stereotypes that were disseminated influenced the educational organization and cooperated to maintain the status quo, that is, inequality and its justifications. Also, to understand the new questions that arise about sexuality, it was necessary to analyze the studies of Louro (1997) and Oliveira e Santos (2012) to understand these new dynamics and perspectives that arise to think about a school concerned with the present, leaving aside your worries about yesterday. Therefore, it was perceived how these relations coexisted and fostered a social organization based on a purpose not only to justify hierarchical power relations, but also to maintain them using strategic sectors such as education and, consequently, the school.
\end{abstract}

Keywords: Gender, Thought, Education, Family, School. 


\section{GÉNERO Y SOCIEDAD: EXPLICACIONES DE SUS RELACIONES Y EFECTOS EDUCATIV}

\section{RESUMEN}

El presente artículo trabaja las concepciones de Vygotsky (1987) sobre la relación entre pensamiento y lenguaje bajo una perspectiva de influencia en el desarrollo cognitivo y en la formación de la visión sobre el género propuesto por la escuela. En este sentido, se observó también la construcción de estereotipos comprendidos por Brunneli (2016) como grandes influencias en el comportamiento social y en el discurso, relacionándose, por esa perspectiva, y mostrándose capaces de explicar acciones e interacciones que son estudiadas por la psicología social. No obstante, se recurrió a los estudios de Cunha y Góes (2002), Xavier, Ribeiro y Noronha (1994) para comprender cómo la formación de esos estereotipos que fueron diseminados influenciaron la organización educativa y cooperaron para el mantenimiento del status quo, es decir, de la desigualdades social y sus justificaciones. Asimismo, para comprender las nuevas cuestiones que surgen sobre la sexualidad, fue necesario analizar los estudios de Louro (1997) y Oliveira y Santos (2012) para comprender esas nuevas dinámicas y perspectivas que surgen para pensar una escuela preocupada con el presente, dejando de lado sus preocupaciones con el ayer. Por eso, fue percibido cómo esas relaciones coexistieron y fomentaron una organización social pautada en un propósito en no solo justificar las relaciones jerárquicas de poder, sino también mantenerlas utilizando sectores estratégicos como la educación y, consecuentemente, la escuela.

Palabras clave: Género, Pensamiento, Educación, Familia, Escuela.

\section{INTRODUÇÃO}

A relação social entre escola e dinâmica social sempre foi muito estudada dentro dos campos da Educação e da Psicologia. Neste sentido, nos propomos a analisar como a escola foi pensada e como influenciou a visão sobre o gênero socialmente, entendendo, de início, a sua participação na formação humanística, como aponta Libâneo (2013) e os desafios deste mesmo espaço social diante de novos pensamentos. Todavia, ressalta-se a necessidade de entender este trabalho como um estudo sobre essas intersecções entre a Psicologia e a Educação, pensando a formação cognitiva e a linguagem sob a tentativa de promover respostas para esses comportamentos. Não estão excluídas, portanto, as preocupações que cercam a construção do pensamento e da sua forma de comunicação, embora desenvolvidas de forma a gerar suas particularidades, compreendidas neste estudo como manifestações coletivas que são reflexos de estruturas responsáveis por dois motores: o primeiro, pelo convívio social - este inegociável na análise - e pela escola responsável por preparar e formar indivíduos capazes de se integrarem em ambientes que os cercam, sendo capazes de interagir, posicionar e ocupar os espaços para valer todos os seus direitos jurídicos e morais.

Ora, o problema, neste aspecto, é cometer o erro de pensar a escola como se estivesse alinhada ao presente. Por isso, justificase a retomada das suas velhas estruturas, embora haja grandes esforços para tornar esse espaço em algo que dialogue de forma concomitante com as novas tendências que surgem diariamente ou podem vir a surgir. Percebendo, neste sentido, o aspecto de sua formação como uma instituição que se prende ao passado. Em outras palavras, a crítica que se deve fazer, de forma pertinente, às escolas é a incapacidade - e não cabe, neste artigo, elencar as razões mas somente as explicações desta afirmação - de desprender-se de um pensamento antigo, de métodos engessados e, de certa forma, refletidos também no seu modo de formar os indivíduos, tornando-se, portanto o objeto principal em análise. Além disso, discutir a formação deles, a qual envolve a capacidade de apresentar explicações de como seus comportamentos são afetados, como, por exemplo, os chamados estereótipos de gênero que influenciam não somente o seu pensamento mas a sua capacidade de inclusão e exclusão em determinado grupo.

Outrossim, coube ao artigo analisar as relações entre o campo social e o campo gerencial da educação para reconhecer as influências de um sobre o outro, compreendendo conceitos que pairam as teorias pedagógicas, a análise no campo da psicologia sobre o pensamento, os aspectos históricos e sociais, a 
emancipação e o descolamento da ideia de gênero da sexualidade. Embora o papel da Escola fosse discutível e por não haver um consenso sobre a sua real participação na constituição social, adotamos o pensamento de Libâneo (2013) sobre as práticas pedagógicas, as quais o autor considera como essenciais para 0 funcionamento social e a existência. Por isso, a tarefa de analisar a complexa relação entre os campos que cercam a educação se torna viável se recorrida, proporcionalmente, aos mesmos espaços de estudos que constroem conscientemente entre si uma linha de raciocínio capaz de explicar as desigualdades sobre o gênero, a etnia e as classes sociais (núcleos constituintes de um ser social).

Por conseguinte, a análise não se restringirá somente ao esclarecimento de questões históricas como trabalhará também os aspectos pedagógicos desse fenômeno, os quais são discutidos em Louro (1994). Logo, o pensamento sobre o gênero deve se adequar ao contexto da época, mas não somente isto como também ao caráter pedagógico com a finalidade de particularizar seu papel e relacioná-los ao comportamento desses gêneros.

Não obstante, entender o papel feminino e sua transformação ao longo do tempo ajudará a entender como o pensamento, cuja base é histórico-cultural (VYGOTSKY, 1987), e a formação desse núcleo se alterou. Ademais, o avanço no campo econômico e a participação feminina no trabalho não acompanhou mudanças significativas em suas estruturas opressoras, sobretudo de comportamentos e de valores culturais (presentes e facilmente reconhecidos) que reafirmam a existência de um sistema patriarcal. A ascensão econômica e a inclusão da mulher como parte da mão de obra para o trabalho transformou a ótica sobre a família cujo papel historicamente era ser responsável pela educação dos filhos e, portanto, tornou a polaridade de identidades mais fragmentada, estruturando um espectro sobre o gênero muito mais abrangente e, consequentemente, mudanças sobre pensar os seus papéis.

Ademais, embora o objeto da análise seja fundamentalmente sobre a figura feminina em oposição ao masculino, evidenciando uma visão polarizada de análise histórico-social, é preciso estender esses princípios e incluir o pensamento sobre a transgeneridade, a qual se tornou um tópico social relevante, apesar de caminhos diferentes, pela sua progressão no campo político alinhado ao discurso feminista. Dá-se conta, assim, que uma estrutura socialmente colocada, isto é, uma base, mesmo que tenha sofrido alterações significativas ao longo do tempo, composta de valores hierárquicos e excludentes, os quais poucos costumam reconhecer nas suas análises associativas. Cabe também elencar que a Educação não deve e, neste artigo especificamente, não é, de fato, o principal "vilão", por mais que se entenda os valores irrefutáveis do processo pedagógico e a importância dessas práticas, os valores culturais construídos historicamente são frutos de associações e dissociações que buscam desequilibrar a balança das relações de poder.

Portanto, o artigo tem como finalidade debater esses processos históricos e entender suas relações com as práticas pedagógicas. Não obstante, discutir sobre as suas práticas atuais, expandindo a sua discussão além de sua polaridade de identidades, incluindo também as representações transgêneras. Ademais, entender como esse debate transgrediu um pensamento que foi reproduzido em um ambiente costumeiramente descrito como não-relacionado ao espaço social, materializando a sua importância em compreender desde os resquícios de pensamento social na organização educacional até o seu reconhecimento atualmente como um dos principais problemas para a promover uma escola inclusiva. Tornar, consequentemente, evidente a necessidade de reconhecer essas práticas nestes ambientes e enfatizar a sua importância, dado que elas foram frutos sóciohistóricos de uma reprodução de pensamento com bases culturais, aliciando-se os conceitos e descobertas às formas de aprender e, tendo a educação como ferramenta, a instrumentalização de uma binarização do reconhecimento do gênero como performance atrelado às estruturas consideradas como pilares no campo de suas relações.

Inclui-se, também, o objetivo em desenvolver explicações que pautam o comportamento infantil e as zonas de influência da escola, compreendendo a sua importância na formação de um indivíduo e a necessidade de pensar novas práticas pedagógicas que deem suporte para novos tipos de sujeitos sociais. Acrescenta-se, também, a tentativa de explicar os conceitos sobre gênero e sexualidade e co mo essas questões aparecem dentro de uma sala de aula, preocupando-se, assim, com a flexibilidade de tratar de temas que são pertinentes à escola, 
tão quanto as matérias determinadas pela Base Curricular Nacional (BNCC). Nesse sentido, entende-se também as estruturas que fomentaram a organização escolar e quais questões contemporâneas podem vir a aparecer sob a perspectiva de um choque entre o novo sujeito, isto é, o aluno trans, e a velha escola, que é responsável pela reprodução de um modelo binário de pensamento sobre o gênero, perspectiva tal que já pode ser encontrada, visto as novas dinâmicas manifestadas em campos do gênero e da sexualidade.

\section{DELINEAMENTO METODOLÓGICO}

De fato, a fundamentação teórica se dá, de forma prioritariamente dita, pela teoria vygotskyana sobre o pensamento e a linguagem e, apesar dela não ser objeto principal da análise, o descolamento de ambos, proposto por Vygotsky (1987) nos fez levantar a seguinte questão considerações feitas sob um olhar contemporâneo, é possível perceber que a construção do pensamento não é propriamente feito no ambiente escolar?

Isto posto, por que reconhecemos em determinados espaços, lugares e classes a figura de um determinado gênero? Por que nos deparamos com lugares onde determinados serviços são dados para mulheres e outros para homens? Coube, portanto, recorrer aos estudos de Brunelli (2016) que respondeu perfeitamente essas questões, baseando-se em pontos de vista da psicologia social. Estes, sendo assim, compõem os discursos que nos rodeiam, e, consequentemente, reverberam-se nos espaços sociais que dispõem-se a enunciá-los. Ademais, o propósito de recorrer a esses estudos é, acima de tudo, entender se a afirmativa vygotskyana tem viés comprobatório e se de fato é possível enxergar essas relações sociais dentro de instituições das quais nos debruçamos a estudar.

Deste modo, Finco (2004) se debruçou na relação entre Educação infantil, a relação de gênero e a brincadeira, onde trabalha com a concepção de que a criança em um contexto escolar tem a possibilidade "de exercer a sua capacidade de estabelecer múltiplas relações e de construir, desse modo, sua autonomia e identidade" (p. 7). Coube, portanto, entender como essas relações entre estereótipos e escola caminham historicamente, sob uma análise sociohistórica, percebendo esses campos de intersecção na formação do pensamento da criança a partir da escola, considerando, entretanto, o seu campo social e as suas manifestações.

Implica-se aqui, neste entremeio entre a organização escolar e os aspectos históricoculturais da educação, o papel do professor. O que esperar dele que, sob uma análise contemporânea, tem o papel de reconhecer os espaços e situações presentes dentro de sala de aulas, sobretudo em seus aspectos sociais? Qual o papel do professor e da Escola nos aspectos inclusivos? Como a Educação pode abraçar o debate sobre transgeneridade e acolher os aspectos da não-binariedade?

Mediante a todas essas questões, recolhemos outras referências que nos ajudaram a pensar as práticas pedagógicas e o ambiente escolar, com a finalidade de aproximar a teoria da prática ao analisar esses aspectos vivos e sociais. A dinâmica na relação entre professoraluno sofreu alterações reconhecidas no campo da prática e da representação, por isso, perceber essas mudanças pressupõe também reconhecer as alterações do tipo de aluno que encontrarão no exercício da profissão, sobretudo as questões que tangem os amplos debates como o gênero, a sexualidade, e, em uma estrutura macro, a relação dele com um mundo. Compreende-se, por fim, que o papel da escola é a preparação do aluno para o convívio social e que a aprendizagem é a finalidade da prática pedagógica, sendo assim, não cabe atentar-se somente ao debate científico e cognitivo, o qual é extremamente importante para o desenvolvimento de habilidades e competências, mas também para o desenvolvimento do pensamento crítico e, consequentemente, o ensino crítico (LIBÂNEO, 2013). Por parte do professor, que não tem como obrigação entender todas as questões que envolvem a sua formação mas tem o papel fundamental de guiar, propor e oferecer caminhos possíveis para temas tão importantes que compõem a compreensão psicológica, biológica e social do próprio ser.

Deste modo, coube recorrer ao Oliveira e Santos (2012) para entender as práticas pedagógicas e o pensar trans como arcabouço teórico para a compreensão dessas questões, a fim de relacionar todos esses apontamentos e promover uma literatura que busca explicá-los e permitir a democratização do espaço escolar, tornando a inclusão de pautas renegadas parte da conversa de dentro de sala de aula, desconstruindo e impedindo a propagação desses 
estereótipos, tornando este movimento de acolhimento menos subversivo.

Neste sentido, o artigo trabalhou responder essas questões traçando relações entre os campos de estudo da psicologia social e da educação, compreendendo as suas influências no comportamento daqueles que desfrutam de ambos os campos, isto é, dos que tiveram sua formação influenciada pela escola e pela sociedade, tentando, desta forma, entender como essa interseção se dá e se é possível delimitar até onde se dará essa influência.

\section{RESULTADOS E DISCUSSÃO}

De início, é preciso pensar que Vygotsky (1987) entende que o desenvolvimento do pensamento e da linguagem não ocorrem de forma dependente, embora apresentou-se, nos seus estudos, "como dois projetos que se intercruzassem em certos momentos e se influenciassem mutuamente duma forma mecânica" (VYGOSTKY, 1987, p. 118). De certa forma, esses processos estão presentes em teorias sociointerativas que buscam explicar a formação e o desenvolvimento cognitivo na criança, partindo, neste sentido, de uma consideração metodológica do espaço além do indivíduo. Porém, não é possível explicar apenas nesse recorte as questões levantadas sobre a sua teoria, ou seja, é preciso tornar mais profunda a análise em sua teoria com a finalidade de promover a relação que se esperava entre os conceitos levantados.

Logo, a compreensão inicial de pensamento e linguagem, neste caso resumida em palavra, pode ser dada pela definição de Vygotsky (1987):

“[...] a relação entre o pensamento e a palavra não é uma coisa mas um processo, um movimento contínuo de vaivém entre a palavra e o pensamento; nesse processo a relação entre o pensamento e a palavra sofre alterações que, também elas, podem ser consideradas como um desenvolvimento no sentido funcional. As palavras não se limitam a exprimir o pensamento: é por elas que este acede à existência. Todos os pensamentos tendem a relacionar determinada coisa com outra, todos os pensamentos tendem a estabelecer uma relação entre coisas, todos os pensamentos se movem, amadurecem, se desenvolvem, preenchem uma função, resolvem um problema." (VYGOTSKY, 1987, p. 124).

Por isso, a percepção do pensamento e a palavra como relação e sujeitas às alterações possíveis tornam a concepção deste estudo mais minuciosa. Seja pela motivação em buscar explicações de como essas alterações ocorrem, seja pelos mecanismos que as provocam. Entretanto, fato é que Vygostsky (1987) percebeu esta relação e descreveu o pensamento como forma de resolução de um problema.

Ademais, Lucci (2006) dedicou-se ao trabalho de explicar sua teoria que estabelecia-se como uma psicologia sócio histórica. Segundo Lucci (2006):

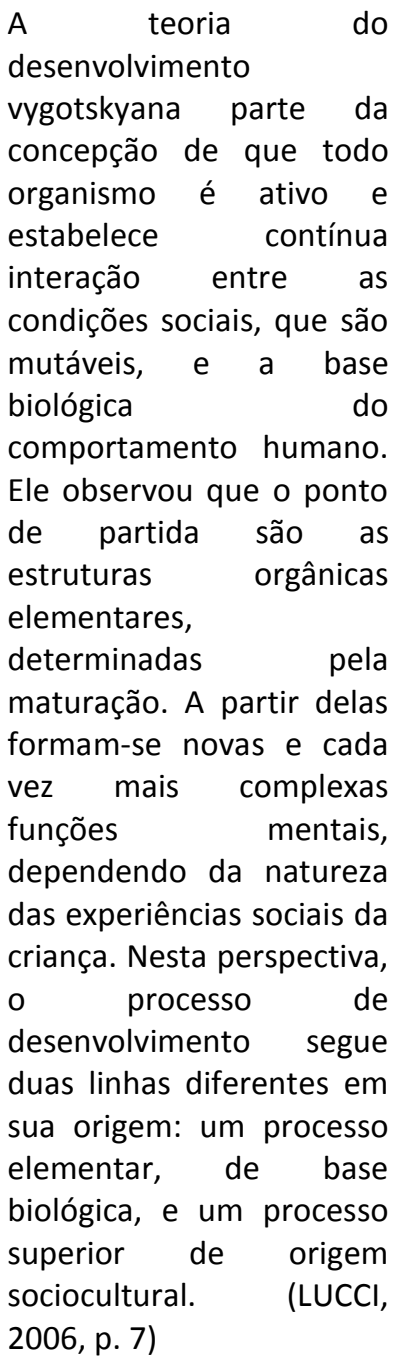


Isto posto, é, dessa forma, necessário descrever o quão importante é associar a formação deste pensamento que tem como constituição a influência do meio externo no qual o indivíduo se integra socialmente. Não obstante, este meio social tem destaque se associamos ao contexto em que se traz todas as organizações educacionais ao longo do tempo e como elas se estabeleceram como forma de gerenciamento.

Doravante, é importante trabalhar com os conceitos trazidos por Brunneli (2016) relacionados aos estudos de estereótipos. Isto posto, eles são "representações cristalizadas sobre um grupo social, esquemas culturais preexistentes, imagens fictícias que expressam um imaginário social." Brunelli (2016, p. 2), ou seja, os estereótipos atuam como uma formação de representações equivocadas de um determinado grupo que atuam na formação de um imaginário sobre ele relacionado às suas características físicas, personalidade, determinam, neste sentido, a sua capacidade ou não de ocupar classes sociais, de realizar determinadas tarefas ou de serem bem ou mal vistos socialmente. Por isso, é importante também dizer que nestes estudos foram percebidos efeitos reais da propagação desses estereótipos, em outros palavras, segundo Brunneli (2016), o comportamento descrito por esses estereótipos podem se tornar verdadeiros, na medida que esses grupos passam a sentir a necessidade de se encaixar nas características que lhe são previstas, colaborando, assim, com justificativas sociais de suas hierarquias.

Neste sentido, há um alerta importante: os estereótipos refletem na estrutura mas só podem ser percebidos criticamente, de uma forma social, com o distanciamento histórico do objeto analisado. Muito embora alguns conceitos sejam muito mais perceptíveis do que outros, a análise desses estereótipos só são permitidas porque há um contraste de ideias, de concepções, de inadequações que foram progressivamente corrigidas ou desconstruídas na sua totalidade. Ou seja, muitas concepções propagadas e tomadas como verdade num senso comum ocuparam espaços consideráveis socialmente, ao ponto de reverberar na concepção de um ou outro determinado grupo, promovendo, portanto, um fenômeno social e comportamental muito particular.

Daí, portanto, a importância deste estudo, pois ele considera também que as propagações destes estereótipos não são tão relevantes quanto a sua difusão, por considerar uma análise crítica marxista de que há uma estrutura que segue hierarquicamente de cima para baixo e que ela é responsável pela formação de valores culturais, concepções, controles dos meios discursivos e econômicos. Sendo assim, esses estereótipos atuam como espécie de justificador das desigualdades sociais, como aponta Brunneli (2013):

Jost e Kay(2005) afirmam que os estereótipos de homens e mulheres são complementares.

Basicamente, isso significa que os estereótipos de gênero sustentam a ideia de que cada gênero é dotado de um conjunto de pontos fortes que equilibra as suas próprias fraquezas (quer dizer, tem um ponto fraco, mas tem um forte também) e compensa, por assim dizer, os pontos fortes do outro grupo. Assim, os estereótipos masculinos mais recorrentes dizem que os homens são competentes, assertivos, independentes e orientados para a realização (qualidades que as mulheres não teriam); as mulheres, por sua vez, seriam afetivas, sociáveis, interdependentes e orientadas para as relações, características que não seriam associadas aos homens. (BRUNELLI, 2016, p.12)

Desta forma, estabelece-se uma estrutura de justificativa social que entende-se, neste sentido, como complementares, tornando esta dinâmica uma relação simbiótica entre as partes. Não é muito complexo entender que a falsa simetria e dependência entre as partes promove uma concepção de ordem e de equilíbrio, tal forma, inclusive, justifica tamanho disparate no pensamentos de políticas públicas e de formação moral entre esses gêneros. Destacase, portanto, algo que Brunneli (2016) ressalta como manutenção do status quo, isto é, de uma estrutura dominante que vê nesses estereótipos um mecanismo efetivo e bem estabelecido. 
Não obstante, entender a relação educacional e este status quo apontado por Brunneli (2016) é compreender como a educação foi organizada do seu período colonial até tempos mais recentes. Colocar, neste sentido, delimitações organizacionais na educação que no período inicial da história brasileira ficou a cargo da Companhia de Jesus, isto é, da Igreja. Custoso seria tentar comprovar algo que vai contra o que o raciocínio lógico sugere, ou seja, pensar que a participação da igreja na educação promoveu ensinamentos que vão, de antemão, romper valores postos pela própria Igreja Católica. $\mathrm{O}$ que se vê, entretanto, é a catequização em seu início, e o apagamento cultural provocado pela cristianização dos povos indígenas e escravos que viviam na colônia.

Todavia, não é a intenção deste artigo discutir esse processo em si, o contexto, na verdade, serve de aparato inicial para entender que as estruturas - embora não possa ser chamada assim já que não eram organizadas controladas pela Igreja só poderiam, de forma natural, seguir ensinamentos propostos por ela e, dessa forma, constituir um pensamento conservador dentro da prática pedagógica e religioso, que promoveu um olhar crítico em relação às questões que envolviam esse processo de forma inexistente.

Xavier, Ribeiro e Noronha (1994) apontam que a educação no período Imperial sofreu vários problemas, sobretudo pelo grande número de analfabetos e pela disparidade de qualidade de estrutura como consequência do federalismo e da autonomia dos estados vigentes. O período da Primeira República foi o período de laicização do ensino e de suas inúmeras reformas, sobretudo porque a sua organização passou a ser uma responsabilidade em âmbito nacional por interesse de opositores ao antigo regime. Outrora o interesse e o "entusiasmo pela educação" fossem características liberais da época, a divisão pelo sexo nas grades continuou como característica na sua organização; deste modo, é incompreensível pensar que pudera ser de outra forma, dado que a educação sempre acompanhou pensamentos culturais de seus respectivos recortes históricos. Deste modo, a mudança de perspectiva dentro da educação não se deu contrariado ao aspecto vigente deste contexto, bem como a ruptura parece pouco presente em sua estrutura; trata-se somente de um interesse econômico que serviu aqueles que tinham em mãos o poder de organizar, pensar e estruturar o sistema educacional para cumprir funções determinadas e necessárias para uma mudança de organização econômica.

Portanto, sob a perspectiva educacional, a estrutura esteve sempre relacionada a forma de pensar o social, de modo a justificar, dentre outras formas, a desigualdade por valores meritocráticos. Se no período Imperial, a educação voltou-se para uma elite portuguesa majoritariamente composta por homens, não medindo esforços para que seu centro acadêmico fosse na metrópole, na Primeira República o interesse era de alfabetizar a população e transformar as práticas pedagógicas, tornando valores como mérito, igualdade de oportunidades e acesso irrestritos indispensáveis como base de suas reformas na teoria. Muito embora seja importante discutir a fundo esse processo, o que nos cabe compreender é como a educação foi dividida, materializando uma forma de pensar o gênero - objeto fundamental de nossa análise.

É, por hora, interessante pensar como desde o período da Primeira República o ensino foi pensado e direcionado a categorizar suas obrigações: separou, em primeiro grau, as etnias; em segundo, separou pelo seu gênero e em terceiro pela sua classe econômica - a ordem, nesse aspecto, não influencia no nosso estudo, o reconhecimento desses recortes é o que direcionou o nosso pensamento, principalmente pelo segundo quesito. Cunha e Góes ( 2002, p. 59) aponta, por exemplo, como no período da Ditadura Militar que teve no "ensino profissionalizante" uma de suas "realizações" mais ambiciosas. Outrossim, as reformas que transformaram o ginásio (2ำ grau) um ensino profissionalizante se encarregou de tornar o ensino de coisas às mulheres como gerenciamento de lar, baseada em estereótipos conservadores como aponta Cunha e Góes (2002):

A educação para o lar reunia outro conjunto de estereótipos acerca da produção. Só que, agora, tratava-se da produção doméstica, de ensinar as meninas - às vezes os meninos, só que não se levava isso a sério - a preparar alimentos e roupas, a conservar a casa, a fazer orçamentos domésticos, tudo dentro 
do mais cândido quadro conservador "daquilo que se chama de lar". (CUNHA; GOES, 2002, p. 63)

O autor aponta também como as reformas feitas no ensino superior foram motivadas pelo grande número de mulheres que cada vez mais tinham interesse em estender seus ciclos de estudos, motivando o investimento em ensino técnico durante o ginásio e, com isso, esvaziando a busca pelo vestibular e entrada nas universidades públicas. Cabe também uma observação de como os responsáveis pela organização dessas reformas compreenderam a necessidade de tornar o ensino profissionalizante para mulheres como uma espécie de, nas palavras de Cunha e Góes (2002), um curso de "espera-marido". Realidade, que outrora pareça distante, é associada no senso comum com cursos de graduação presentes - aqueles, como explicamos sobre os estereótipos trazidos de Brunneli (2016), constroem visões imaginárias e limitadas que relacionam classes e espaços sociais aos gêneros que comumente são descritos como modelos de análise.

Por essas duas perspectivas, é possível entender como o meio social se relaciona com a forma de educar. Não obstante, entende-se também como essa organização educacional moldou uma pavimentação de pensamento já existente, que por si só era binário, estruturalmente desigual e que visava a disparidade e não sua aproximação; por menores, descritos esses processos culturais e, especificamente, sociais em âmbito nacional, entende-se, de forma concreta, que a relação histórico-cultural existente molda, majoritariamente, o nosso pensamento.

Contudo, compreende-se a educação como transmissão cultural de valores; pensar a educação e planejá-la desta forma moldou não somente o pensamento de seus educandos como moldará também o pensamento de seus próximos educadores; estruturar a educação para compreender a relação de gênero como binária e hierárquica resulta em réplicas desse comportamento na formação do ser social como todo. Ao desenvolver-se e tornar-se consciente, a criança domina a tarefa e organiza, ela própria, o seu conhecimento.

A criança "se percebe e percebe a realidade circundante e contextual, toma consciência de suas vivências. A tomada de consciência, a percepção de si, direciona a criança à autonomia, o que lhe possibilita experimentar ser o eu e ser o outro" (ALBERTO e SANTOS, 2011); assim sendo, imaginar a escassez de modelos oferecidos, a rigidez da forma de ensinar sobre seus comportamentos, ou a restrição de sua liberdade de pensamento produz uma binariedade consciente, da qual se encarrega de reconhecer espaços para determinados gêneros, atribuir determinadas funções a eles e, portanto, hierarquiza automaticamente suas relações.

Daí a importância da discussão pedagógica sobre as cercanias do gênero e da biologia, que "se transforma em um objeto de investigação sociológica e histórica" (FINCO, 2004 , p. 14) , e sua abordagem em sala de aula, além de um caminho para ultrapassar as barreiras que ainda hoje são tabu em nossa sociedade, a pedagogia, anexa a outros esforços, certamente, possui um grande potencial de devolver àqueles marginalizados seu direito inalienável: o direito à humanidade. Se fora da escola, a busca pela equidade se fez incessante durante este período, cabe dentro dela promover práticas pedagógicas que conciliam pensamentos acerca de seus corpos, porque o trabalho pedagógico é fundamental na criação da condição e na abertura de novas formas de participação da criança na cultura (ALBERTO e SANTOS, 2011).

Como apontado anteriormente, seguindo as linhas do estudo historiográfico de Cunha e Góes (2002), a escola, juntamente do discurso sobre seu propósito, já assumiu papéis multifacetados, alinhados à cultura de determinados espaços temporais, ou advinda das ideologias dos líderes. Visto que hoje, com a superação do estruturalismo na educação, os caminhos percorrem a discussão do gênero, atualmente, em sala de aula, em meio a uma sociedade que faz da religião, classe social e vários outros dogmas, a via para lidar (ou não) com suas questões? Ou então, que pensamentos e caminhos humanizadores queremos garantir dentro da sala de aula? E para além da educação?

O desafio que está para além da educação, claro, não cabe ser tratado em sala de aula, mas sim na vida pública, com garantias de que a decisão pela educação seja a de libertar, e não reproduzir a opressão - garantir isso é de suma importância para a educação dentro das salas. Entretanto, a escolha aparente por não tratar da sexualidade dentro das escolas é não só 
irracional, como perniciosa; não existe a separação "indivíduo e sexualidade", ela está para o indivíduo assim como a linguagem. E ainda sim esta dicotomia se encontra presente nas escolas, bem como, desde os primeiros estágios de aprendizagem da criança, por simples brincadeiras, cores e dizeres, são ensinados a reproduzir a dicotomia de gêneros, por exemplo: quando aos meninos é reservado o futebol e às meninas o ballet. Essa cultura, anexa à linguagem binária que permeia a sociedade, será internalizada e passada adiante pelo aluno, e logo será nocivo no processo de desenvolvimento como expõe Vygotsky (1987).

É necessário que o ambiente dentro da escola não se utilize da linguagem para oprimir, ao mesmo passo que fora dela ocorram mudanças, já que o processo da educação é dialético e não ocorre isolado de seu entorno. Ao garantir mudanças na ordem vigente, que a muito se construiu estabelecendo a heterossexualidade como "natural", garante-se que o futuro seja mais justo para todas as pessoas - as mudanças que surgiram com a luta feminista, como avanços na ciência, cultura, filosofia e tantas outras áreas são indubitáveis. Contudo, a violência ainda é uma realidade chocante, os números anuais de agressões contra mulheres, trans e homossexuais continuam sendo alarmantes e muito flutuantes - flutuam sim de acordo com a linguagem nos entremeios político-sociais. Não obstante, avança entre as várias instituições e é reproduzida na escola e fabricada juntamente do indivíduo que vem a se desenvolver de forma fragmentada quando sua sexualidade é tomada de si.

Figura: Atlas da violência 2019

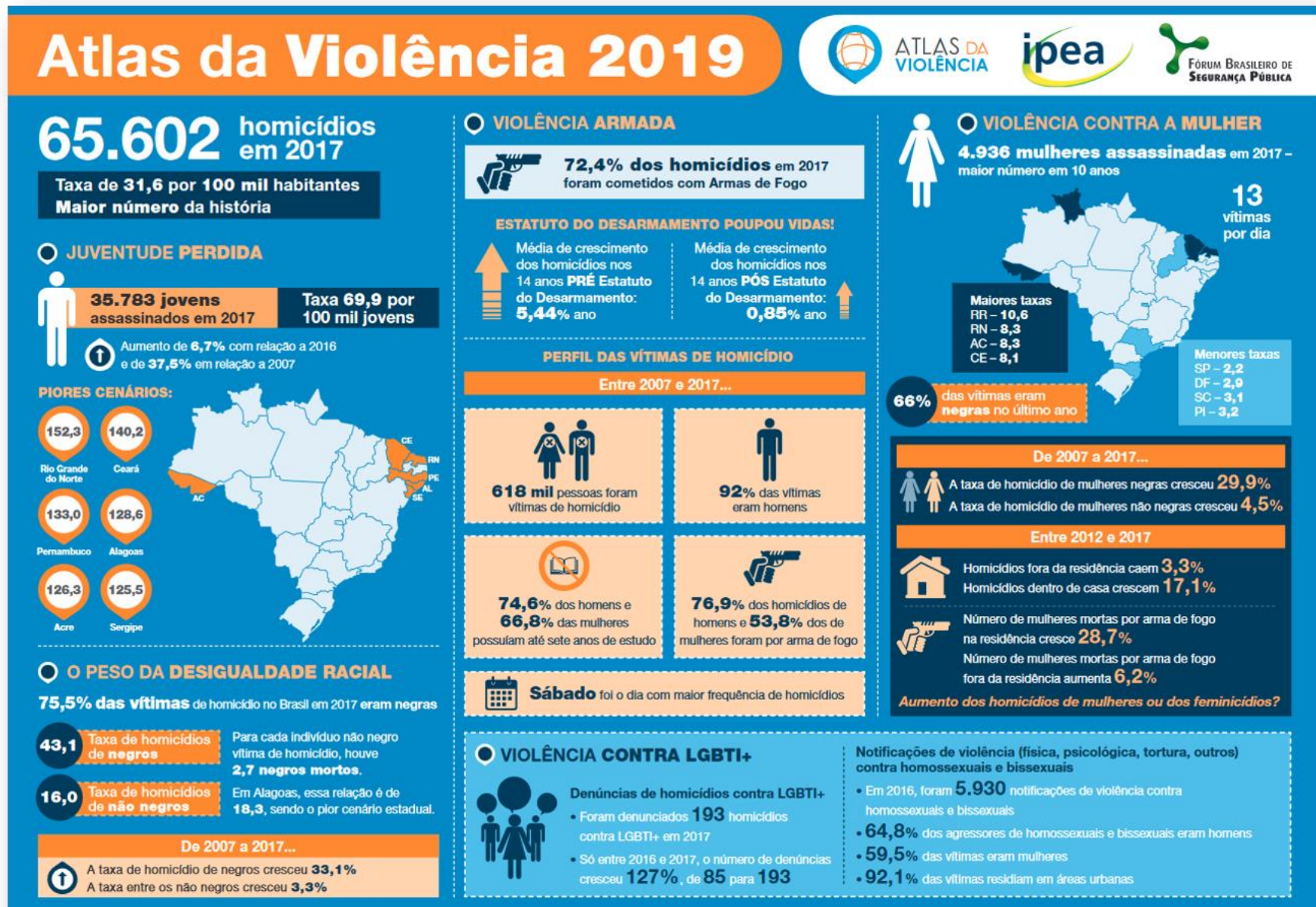

Fonte: Rede SUAS, 2019. Disponível em: http://blog.mds.gov.br/redesuas/dados-sobre-violencia-no-brasil/. Acesso em: 27 set. 2021. 
Como é possível perceber esta violência pelo infográfico ${ }^{1}$ disponível, os números cresceram e os seus recortes sociais e de gênero não podem, e nem deveriam, ser ignorados. Logo, ao perceber as relações entre crescimento das taxas de violências, percebemos que o núcleo que envolve mulheres, LGBTI+, contra homossexuais e bissexuais sofrem um aumento significativo. Por isso, o debate sobre a violência simbólica, colocado por Bourdieu e Passeron (1992), é necessário pela capacidade dela em impor uma cultura que justifique a desigualdade e repressão daqueles que sofrem deste mesmo mecanismo.

Não é papel da escola demarcar as relações desiguais de poder entre o que é ditado como certo ou errado, bem como não é o objetivo a luta para a emancipação das mesmas, mas, nas palavras de Louro (1997), aos compromissados com o ensino cabe "adotar uma atitude vigilante e contínua no sentido de procurar desestabilizar as divisões e problematizar a conformidade com o "natural"; isso implica disposição e capacidade para interferir nos jogos de poder."

A discussão da sexualidade e das questões de gêneros geralmente é relacionada com a educação sexual. Mas se já não bastassem os problemas associados ao tema da educação sexual nas escolas, que por vezes trata como natural, desejável e moral somente as relações heteronormativas, existe a questão de que tratar desses temas somente em aulas de ciências ou biologia, além da associação com infecções sexualmente transmissíveis geralmente feita nessas aulas, significa negar o aspecto social tão fundamental das questões de gênero, diversidade de sexo e orientação.

É notória a necessidade da adoção de estratégias pedagógicas em sala de aula que visem discutir as questões de gênero e a teoria Queer, suprimindo as desigualdades de gênero. As pedagogias formuladas sobre o ponto de vista feminista têm por base o reconhecimento das diferenças existentes com o objetivo de superálas, mas, segundo Louro (1997), tal superação deve se dar dentro dos jogos de poder existentes, pois foi justamente a partir desses jogos que as feministas avançaram até aqui.

Uma questão fundamental na busca pela igualdade de gênero nos espaços educacionais transcende tais espaços e está ocorrendo em todo o âmbito social. É um movimento da sociedade na direção do questionamento e da crítica à existência dessas desigualdades que vêm diminuindo a resistência de todas as instituições sociais com relação às questões de gênero. Por isso, a busca pela igualdade de gênero no âmbito escolar, significa, tendo por base as análises e construções teóricas que estão sendo realizadas, criticar, questionar, colocar-se no debate público e, assim, combater no espaço político as desigualdades no âmbito social.

O papel que o professor e outros intelectuais que estão comprometidos com a causa da igualdade de gênero nestes dias de pósmodernidade deve ser 0 de combater as estruturas da desigualdade no cotidiano. Atualmente, as lutas têm um âmbito muito mais localizado do que anteriormente, mas elas precisam ser travadas, pois são nestas oportunidades de discussão do cotidiano em que a consciência coletiva poderá progredir ainda mais na direção da aceitação das questões de gênero como fundamentais.

Além disso, o questionamento e o reconhecimento das desigualdades devem ser trabalhadas em sala de aula, como prática pedagógica, exercitando o senso crítico dos alunos em relação às representações de gênero trazidas pelos livros didáticos, jornais, revistas e etc., refletindo sobre tais representações e identificando as desigualdades a fim de revelá-las e refutá-las com os alunos. A partir desse tipo de estratégia será possível estabelecer oposição à estrutura escolar tradicional e patriarcal.

Nas escolas a palavra trans surge quase exclusivamente relacionada à educação sexual, geralmente designando uma identidade de gênero, no entanto, trans, de acordo com Oliveira e Santos $(2012$, p.4), é um conceito que vai muito além da identidade e tem o poder de levar à reflexão sobre o que é ser trans e que pode ser aplicado a todo tipo de conhecimento, pois trans significa transformação, a possibilidade de mudar, "reorganizar, reconstruir e construir" (OLIVEIRA e SANTOS, 2012, p.4).

Podemos apostar em uma
pedagogia que não é
instrumento para a
transmissão de uma
verdade teórica ou moral
nem para a projeção
explícita de como
deveríamos ser, em que
deveríamos acreditar e
como deveríamos nos
portar; mas, sim, para a
interrupção constante de

Podemos apostar em uma pedagogia que não é instrumento para a transmissão de uma verdade teórica ou moral nem para a projeção explícita de como deveríamos ser, em que deveríamos acreditar e como deveríamos nos interrupção constante de 
toda a pretensão de imposição da verdade e para a suspensão permanente de toda tentativa de fixação de projeto. Temos a desconfiança que, aqui, o Trans enquanto performance política pode ensinar à pedagogia mais do que podemos imaginar. (OLIVEIRA; SANTOS, 2012, p. 11).

Ou seja, é necessário assumir a própria pedagogia como trans (transpedagogia) para subverter os conceitos patriarcais tradicionais e cristalizados da velha pedagogia, pois a pedagogia precisa ser transformadora, assim como o é a experiência trans. Uma pedagogia que não ensine verdades, mas que transmita o mundo como o organismo vivo e em constante mudança que ele é. Com diversas culturas, experiências e visões de mundo cada uma com suas próprias convicções, todas passíveis de serem compartilhadas e conhecidas. A pedagogia deve aprender com as/os trans a respeitar e valorizar toda essa diversidade sexual que pode haver no mundo e jamais ensiná-las como verdades imutáveis.

Uma política Trans para uma pedagogia é aquela que afugenta o caminho fácil em que todo mundo já sabe o que é hoje e o que será amanhã [...] para desfazer o já feito e o já dito das pedagogias de gênero e sexualidade (OLIVEIRA; SANTOS, 2012, p. 14).

Portanto, seja qual for a pedagogia adotada em sala de aula, é responsabilidade do professor enquanto sujeito intelectual em tempos pós-modernos, como define Louro (1997), aprimorar suas estratégias pedagógicas com o conceito do/a trans de Oliveira e Santos (2012) e traduzir tais estratégias como práticas pedagógicas comprometidas com esses princípios, não transmitindo verdades absolutas, mas sim ensinando a viver e experienciar o mundo e suas possibilidades.

\section{CONCLUSÃO}

Trabalhou-se neste presente artigo as concepções de Vygotsky (1987) sobre o pensamento e linguagem buscando explicar as relações que esses dois campos estabelecem no desenvolvimento cognitivo. Outrora fosse possível explicar de forma simples a sua teoria, entretanto, o que se entende é que a concepção vygotskyana pautou muitos conceitos que the precederam na psicologia.

Ademais, a análise do campo comportamental se estendeu às análises feita por Brunneli (2016) em relação aos estereótipos, compreendendo como eles influenciam a forma que delimitamos nossas impressões sobre determinados grupos sociais, associando-os com determinadas características físicas e personalidade, pautando, de certa forma, uma visão social, neste caso, do gênero e suas atribuições. Não obstante, a análise sobre os estereótipos pautou-se na relevância em destacar que elas, sob o ponto de vista elencado no estudo, justificaram uma desigualdade social pelas motivações postas, e retomadas aqui, como complementares. Logo, o equilíbrio pela sua desigualdade em atribuições, em classe, em formação, era e ainda é um argumento levantado para a sua manutenção.

Neste sentido, buscamos na literatura sobre educação elencar os principais movimentos históricos que revelam, na sua organização, a validação desses estereótipos estudados pela psicologia social nos quais demonstram, de forma explícita, o pensamento sobre esses gêneros de forma diferentes e pautados numa concepção social do feminino e masculino os quais foram construídos em prol da manutenção do status quo já mencionado.

Ora, neste sentido, explicou também que não é papel da escola manter essas estruturas e sim oferecer um ensinamento crítico em relação a elas, de forma a perceber as suas nuances e manifestações, pois é nesse sentido que a construção de indivíduo capaz de conviver socialmente terá ferramentas necessárias para adequar-se ao meio em que será inserido, dotando de todos os meios, inclusive, para mudálo a partir do seu pensamento crítico. Por isso, pensar a transgeneridade dentro da prática pedagógica precisa ser incluída, visto que esse tema deve ser de interesse da escola e, consequentemente, da educação se quiser cumprir o seu dever de formação.

Indivíduos, inclui-se aqui esses corpos trans, são mutáveis socialmente e devem ter os seus conceitos desconstruídos, questionados e 
revistos. Com a finalidade de tornar a escola preocupada com o presente, é necessário pensála sob a perspectiva de novos desafios, novos corpos, e novas dinâmicas sociais que podem vir a aparecer durante o período, não restringindose, assim, dos valores estabelecidos em outras épocas que tornam o diálogo e relação professoraluno uma leitura, quase sempre, desinteressante do ponto de vista cotidiano.

Por fim, pontua-se como limitação da pesquisa a incapacidade de promover grandes soluções para estes desafios. É preciso, entretanto, promover a busca pelos problemas e apontá-los, pois somente desta forma é possível fazer uma busca assertiva e engajada de soluções para promover uma educação mais inclusiva, menos engessada e que seja capaz de direcionar o aluno para uma sociedade "do hoje", e não do "ontem".

\section{CONFLITO DE INTERESSE}

Os autores declaram não haver qualquer potencial conflito de interesse que possa interferir na imparcialidade deste trabalho científico.

\section{REFERÊNCIAS}

ALBERTO, M. F. P.; SANTOS, D. P. Trabalho infantil e desenvolvimento: reflexões à luz de Vigotski. Dossiê - Diálogos com Vigotski: Psicologia, Educação e Arte - Psicol. Estud. 16 (2) • aceito em 04/06/2011. Disponível em: https://www.scielo.br/i/pe/a/GSqxVKZ57wRDVv3 Yy7D3gJB/?lang=pt. Acesso em: 10 maio 2021.

BOURDIEU, Pierre.; PASSERON, Jean Claude. Livro I: fundamentos de uma teoria da violência simbólica. In: _. A reprodução: elementos para uma teoria do sistema de ensino. 3. ed. São Paulo: Francisco Alvez, 1992.

BRUNELLI, A. F. Estereótipos e desigualdades sociais: contribuições da psicologia social à análise do discurso. Cadernos de Estudos Linguísticos, Campinas, SP, v. 58, n. 1, p. 25-43, 2016. DOI: https://doi.org/10.20396/cel.v58i1.8646152

CERCARE et al. Atlas da violência 2019. Brasília, DF: Rede SUAS, 2019. Disponível em: http://blog.mds.gov.br/redesuas/dados-sobreviolencia-no-brasil/. Acesso em: 27 set. 2021.
CUNHA, L. A.; GÓES, M. 0 golpe na educação. 11. ed. Rio de Janeiro: Jorge Zahar Ed., 2002. p. 3587.

FINCO, Daniela. Faca sem ponta, galinha sem pé, homem com homem, mulher com mulher: relações de gênero nas brincadeiras de meninos e meninas na pré-escola. 2004. 171 f. Dissertação (Mestrado em Educação) - Universidade Estadual de Campinas, Faculdade de Educação, Campinas, SP, 2004. Disponível em:

http://www.repositorio.unicamp.br/handle/REP OSIP/252827. Acesso em: 16 maio 2021.

LIBÂNEO, J. C. Didática. 2. ed. São Paulo: Cortez, 2013.

LOURO, G. L. Gênero, sexualidade e educação: uma perspectiva pós-estruturalista. Petrópolis, RJ: Vozes, 1997.

LUCCl, Marcos A. A Proposta de Vygotsky: a psicologia sócio histórica. Profesorado (Granada), v. 10, p. 01-10, 2006.

OLIVEIRA, T. R. M. DE; SANTOS, C. Novos mapas de (trans) sexualidade e de gênero: pistas para pensar políticas trans e práticas pedagógicas. Revista Cronos, v. 11, n. 2, 2012.

RIBEIRO, M. L. S. História da educação brasileira: a organização escolar. 12. ed. São Paulo: Cortez: Autores Associados, 1992. (Coleção educação contemporânea).

VYGOTSKY, L. S. Pensamento e linguagem. 1. ed. São Paulo: Martins Fontes, 1987.

VYGOTSKY, L. S. Imaginação e criação na infância. (A. M. B. Smolka, Trad.). São Paulo: Ática, 2009.

XAVIER, M. E. S. P.; RIBEIRO, M. L. S.; NORONHA, $O$. M. História da educação: a escola no Brasil. São Paulo: FTD, 1994. p. 102-121. 